\title{
Comprehensive evaluation of effects and safety of statin on the progression of liver cirrhosis: a systematic review and meta- analysis
}

Yue Gu${ }^{1}$, Xueqin Yang ${ }^{2}$, Hang Liang ${ }^{3}$ and Deli Li ${ }^{*}$

\begin{abstract}
Background: Statin has been more and more widely used in chronic liver disease, however, existed studies have attained contradictory results. According to the present study, we aimed to test the efficacy and safety of statin via a meta-analysis.

Methods: Different databases were searched for full-text publication based on inclusion and exclusion criteria. For data-pooling, fixed-effect model was applied if heterogeneity wasn't detected. Otherwise, random-effect model was adopted. Heterogeneity was detected by I squire $\left(I^{2}\right)$ test. All results of analysis were illustrated as forest plots. Publication bias was assessed using the Begg's adjusted rank correlation test. Standard mean difference (SMD) was calculated in continuous variables. Pooled hazard ratio or odds ratio was calculated in catergorical variables.

Results: Seventeen clinical studies were finally included. Hepatic portal hemodynamic parameters were improved in statin users for a short-term response. For a long-term follow-up, statin treatment surprisingly decreased mortality rate $\left(\mathrm{HR}=0.782,95 \% \mathrm{Cl}: 0.718-0.846, P^{2}>50 \%\right)$ and lower the occurrence of hepatocellular carcinoma $(\mathrm{HR}=0.75,95 \% \mathrm{Cl}$ : $0.64-0.86, P^{2}>50 \%$ ) in liver cirrhosis. Statin seemed not to decrease the risk of esophageal variceal bleeding and spontaneous bacterial peritonitis. However, statin was proved to decrease the risk of hepatic encephalopathy and ascites. Incidence of drug related adverse events didn't increase in statin users. Dose-dependent effects of statin on hepatocellular carcinoma development, decompensated cirrhosis events occurrence, and liver cirrhosis progression.

Conclusion: Statin influenced parameters of hepatic portal vessel pressure in short-term treatment. Prognosis of liver cirrhosis benefited from statin treatment in long term follow-up. The efficacy and safety of statin in liver cirrhosis treatment is confirmed. To date, similar study is hardly seen before.
\end{abstract}

Keywords: Statin, Liver cirrhosis, Portal hypertension, Complication, Meta-analysis

\section{Background}

The major causes of liver cirrhosis are: alcoholic liver disease (ALD), chronic viral hepatitis (chronic hepatitis B, chronic hepatitis $\mathrm{C}$ ), non-alcoholic fatty liver disease (NAFLD) or non-alcoholic steatohepatitis (NASH), and others such as primary biliary cholangitis (primary biliary cirrhosis, $\mathrm{PBC}$ ), primary sclerosing cholangitis (PSC), autoimmune hepatitis, hemochromatosis, Wilson's disease,

\footnotetext{
* Correspondence: 11202997@qq.com

${ }^{3}$ Department of Pediatric Respiratory II, First Hospital of Jilin University, No. 1 Xinmin Street, Changchun 130021, Jilin, China

Full list of author information is available at the end of the article
}

alpha-metabolic diseases such as: 1-antitrypsin deficiency, galactosemia and glycogen storage disorders, and heart failure with liver congestion [1]. After liver cirrhosis developed into decompensated cirrhosis, mortality rate would astoundingly increase [2]. Nowadays, liver cirrhosis has become one of the most deadly disease all over the world [3, 4], and hepatic encephalopathy, variceal haemorrhage, spontaneous bacterial peritonitis, and hepatocellular carcinoma (HCC), etc. are listed as the main cause of death in liver cirrhosis [5]. The disease progression could be hardly reversed when decompensated liver cirrhosis is developed, and therefore, early intervention of preventive medication

C The Author(s). 2019 Open Access This article is distributed under the terms of the Creative Commons Attribution 4.0 International License (http://creativecommons.org/licenses/by/4.0/), which permits unrestricted use, distribution, and reproduction in any medium, provided you give appropriate credit to the original author(s) and the source, provide a link to the Creative Commons license, and indicate if changes were made. The Creative Commons Public Domain Dedication waiver (http://creativecommons.org/publicdomain/zero/1.0/) applies to the data made available in this article, unless otherwise stated. 
may play an important role to fight against liver cirrhosis and improve its prognosis.

Statins is a set of lipid-lowering agents by targeting at inhibiting the activity of 3-hydroxy-3-methylglutaryl coenzyme A (HMG-CoA) reductase, resulting in inhibition of cholesterol generation and serum cholesterol levels downregulation [6, 7]. Except for its well-acknowledged function, decreasing serum low density lipoprotein $C$ cholesterol, statin is also believed to alleviate oxidative stress injury, prohibit inflammatory cell activation, reduce the level of inflammation reaction, and improve endothelial function through a nitric oxide synthase dependent pathway [8-11]. Recent years, statin has been more and more widely used in chronic liver disease [12, 13], and it draws a lot of interests in investigating the good effects of statins on the primary prevention and secondary prevention of liver cirrhosis. Retrospective cohort studies in large populations of patients with cirrhosis and pre-cirrhotic conditions have shown that treatment with statins, with the purpose of decreasing high cholesterol levels, was associated with a reduced risk of disease progression, hepatic decompensation, hepatocellular carcinoma development, and death. Finally, a few randomised controlled trials (RCTs) have shown that treatment with simvastatin decreases portal pressure (two studies) and mortality (one study). Statin treatment was generally well tolerated but a few patients developed severe side effects, particularly rhabdomyolysis. Despite these promising beneficial effects, further RCTs are required, with larger patient series and hard clinical endpoints should be performed before statins can be recommended for use in patients with chronic liver disease [14-19]. However, statins itself could lead to hepatic dysfunction [6], especially in combination with the drug which is metabolised by cytochrome P450 enzyme system [20]. Considering the potential hepatotoxicity of statins, its benefits in liver cirrhosis might be dampened. Besides, existed studies concerning statins treatments in preventing liver cirrhosis have attained contradictory results somehow [21-37]. Consequently, a systematic study to synthesize data from different studies to test the efficacy and safety of statin in liver cirrhosis treatment is highly needed. To date, similar study is hardly seen before, so that we aim to comprehensively evaluate the statin on liver cirrhosis and its development.

\section{Methods}

\section{Search strategy}

This study design was stringently conformed to the Preferred Reporting Items for Systematic Reviews and MetaAnalyses (PRISMA) statement [38]. Five databases, namely Pubmed, MEDLINE on Ovid, EBSCO, Web of Science, and the Cochrane Library, were searched as mentioned before with key words such as statin, liver cirrhosis, hepatic portal hypertension, decompensated cirrhosis, and complication to retrieve related literature published before June 2019.

\section{Study selection criteria and data extraction}

Two investigators who were not informed with the protocol of the present study checked the quality and eligibility of all retrieved studies and collected the data independently. The finally included literature met criteria as follows: English language; comparison between statin treatment group and non-statin treatment group; with full-text instead of abstract only; clear definition of decompensation events of liver cirrhosis and statin related complications, e.g. variceal haemorrhage, ascites, hepatic encephalopathy, diarrhea, and myalgia, etc. Exclusion criteria included: animal studies (basic research); case-reports, case-series, and reviews articles; acute hemodynamic study. In cases of different publications from the same study, the one with the most complete data was chosen. Interested data such as the number of total patients and the number of patients with clearly defined events were carefully collected. Besides, basic demographic data and follow-up duration were collected as well [39-42].

\section{Data synthesis and statistical analysis}

If non-heterogeneity was detected, fixed-effects models were introduced to integrate data to compare statin treatment or not in the difference of short term follow-up and long term follow-up. Other than, the random-effects models were adopted. Heterogeneity was detected by I squire $\left(I^{2}\right)$ test. Heterogeneity was defined as $I^{2}<50 \%$, and the value of $I^{2}$ was shown in the forest plot. Results were presented as pooled hazard ratio (HR) or pooled odds ratio (OR). All results of analysis were illustrated as forest plots to make them visualizable. Additionally, publication bias was assessed using the Begg's adjusted rank correlation test and shown as funnel plot [39-44], and Additional file 1: Figure S1 showed the typical diagram of publication bias analysis. The Newcastle-Ottawa Scale was used to evaluate the quality of each study independently, and quality assessment results were presented in Table 1.

\section{Statistics}

Statistical heterogeneity was measured using the Inverse Variance (I-V) statistics. Statistical analyses were performed using Stata software 12.0 (Stata Corp, College Station, Texas). Standard mean difference (SMD) was calculated in continuous variables, and pooled HR value or pooled OR value was calculated in catergorical variables. All $p$ values were 2 -tailed, and the statistical significance was set at 0.05 (95\% confidence interval).

\section{Results}

\section{Demography of included studies at baseline}

Literature search, data extraction, and general description of included studies were carried out by two independent researchers. Total of 1776 articles was searched after excluding 176 duplications. Six hundred sixteen 


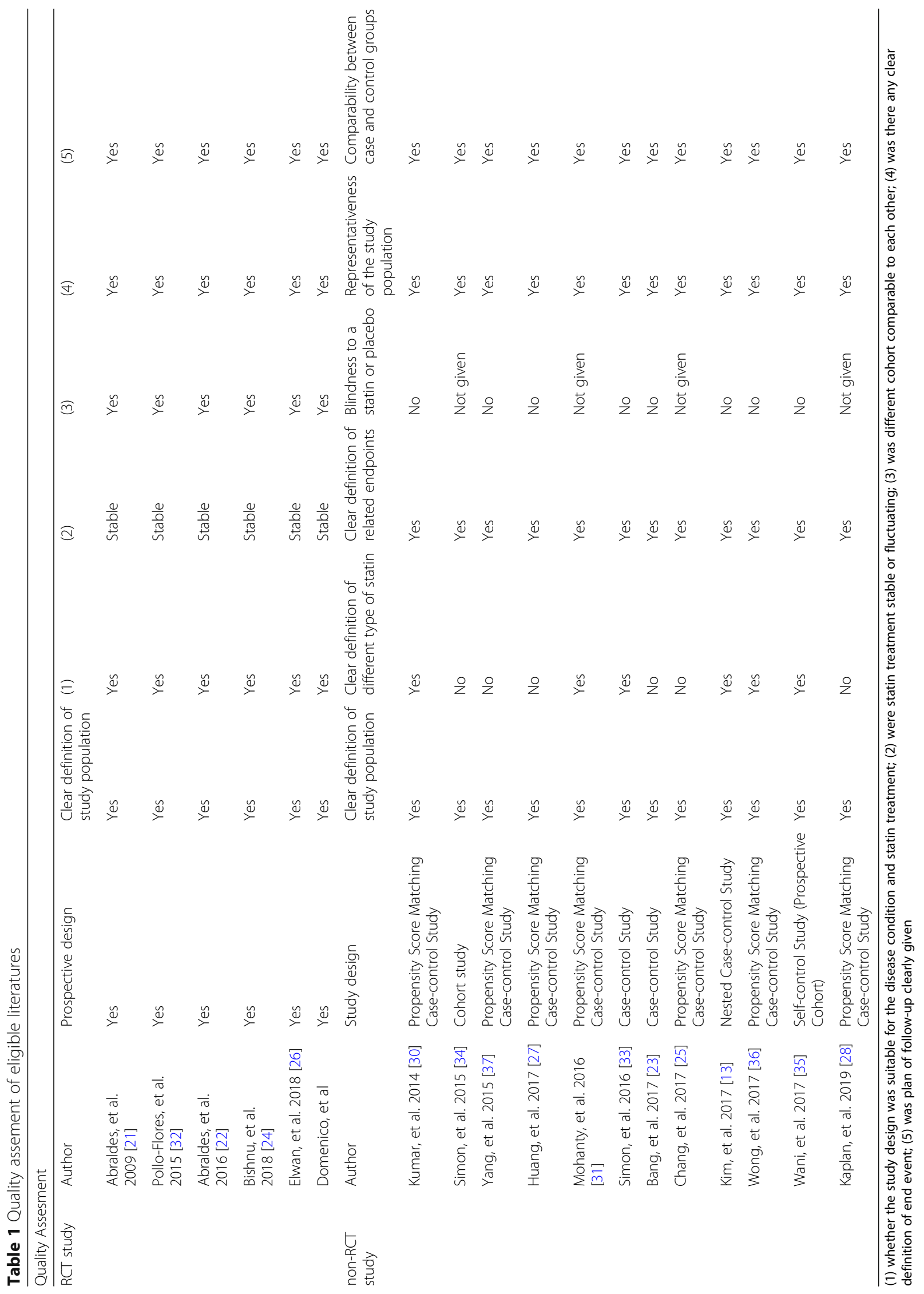


articles were excluded afterwards for not meeting the inclusion/exclusion criteria. Based on the aim of the present study, 17 clinical studies were finally included [21-37]. The flow diagram of publication filtration was shown in Fig. 1. Demographic data of patients with short term follow-up and long term follow-up were pooled together, respectively. The characteristics of included studies were generally described in Tables 2 and 3 .

\section{Statin influenced parameters of hepatic portal vessel pressure in short-term treatment}

Five studies [21, 24, 26, 32, 35] reported parameters of hepatic portal vessel pressure with follow-up duration less than 3 months. In these studies, three important hepatic portal hemodynamic indexes, hepatic venous pressure gradient (HVPG), free hepatic vein pressure (FHVP), and wedged hepatic venous pressures (WHVP) which could reflect the degree of portal hypertension, were included. Since these parameters were continuous variables, pooled SMD was calculated. Statin treatment could significantly decrease the value HVPG comparing with control group $\left(\mathrm{SMD}_{\mathrm{HVPG}}=-1.146,95 \%\right.$ confidence interval (CI): $\left.-1.3120-0.981, I^{2}>50 \%\right)$. However, compared to patients without statin treating, patients receiving statin intervention was proved to fail to lower value of FHVP and WHVP $\left(\mathrm{SMD}_{\mathrm{FHVP}}=0.3\right.$, 95\% CI: $0.13-$ $0.47, I^{2}>50 \%$ and $\mathrm{SMD}_{\mathrm{WHVP}}=0.2,95 \% \mathrm{CI}: 0.03-0.37$, $\left.I^{2}<50 \%\right)$, respectively. Consequently, HVPG was verified under condition of statin taking (Fig. 2a). Unfortunately, FHVP and WHVP may not be sensitive enough to detect the difference. It meant that even though a short-term exposure to statin, the portal hypertension could be alleviated (Fig. $2 b$ \& c).

\section{Prognosis of liver cirrhosis benefited from statin treatment in long term follow-up}

Influence of statin in survival rate, decompensation events of liver cirrhosis, and HCC were investigated for long term follow-up as long as 14 years, and related data was extracted and analyzed to interpret the effect of statin. Statin treatment surprisingly improved survival rate in liver cirrhosis $\left(\mathrm{HR}=0.782,95 \%\right.$ CI: $0.718-0.846, I^{2}>$ $50 \%$ ), and the decreased risk of mortality as a hard clinical end-point persuasively verified the beneficial effects of statin (Fig. 3a). Decompensation of liver cirrhosis included variceal haemorrhage, hepatic encephalopathy, ascites, and even spontaneous bacterial peritonitis. Studies which had reported the incidence of the total decompensated cirrhosis events were analyzed, and the pooled data suggested statin treatment could decrease the occurrence of decompensated cirrhosis events (pooled $\mathrm{HR}=0.658,95 \%$ CI: $\left.0.483-0.833, I^{2}<50 \%\right)$ after longterm follow up. Although decompensation events of liver cirrhosis were decreased (Fig. 3b), subgroup analysis of each specific decompensated cirrhosis event was applied (Fig. 3c-f). Statin seemed not to decrease the risk of esophageal variceal bleeding (Fig. 3c) and spontaneous bacterial peritonitis (SBP) (Fig. 3d). However, statin was proved to decrease the risk of hepatic encephalopathy (Fig. 3f) and ascites (Fig. 3f). As one of the most serious

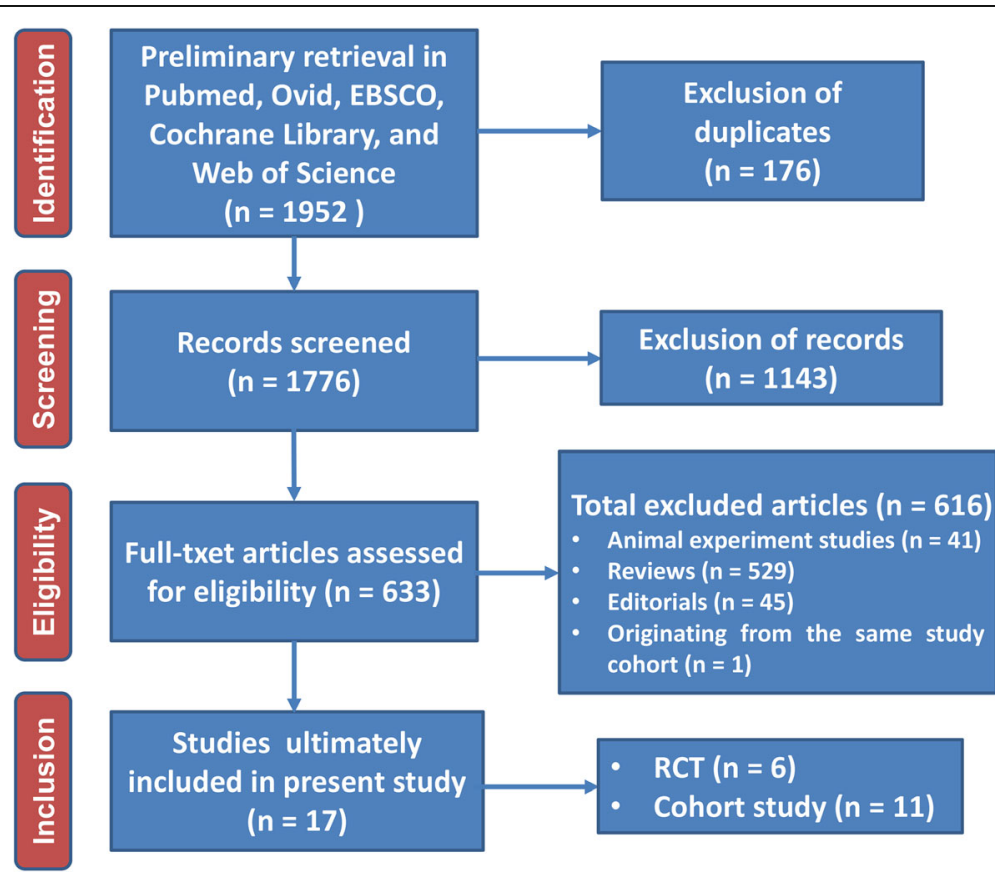

Fig. 1 Flow diagram of literature filtration 


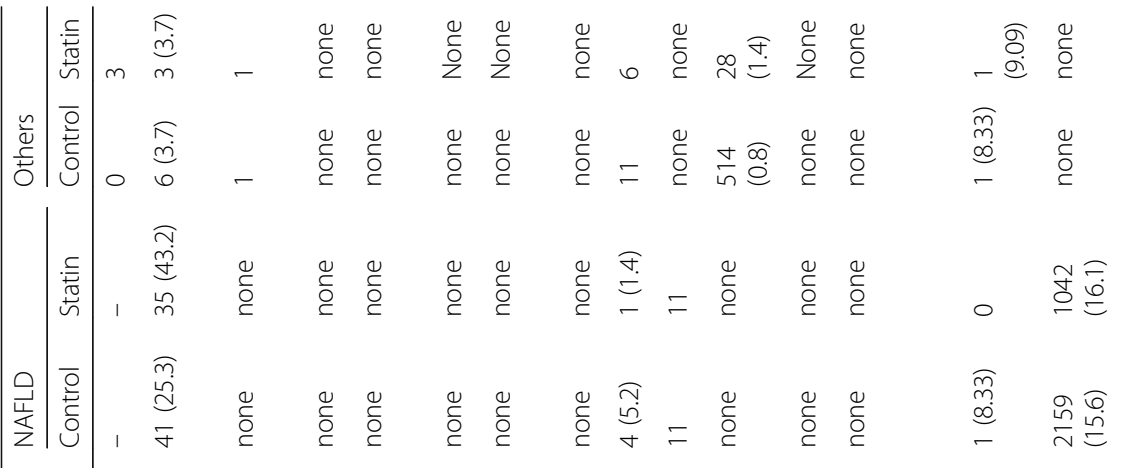

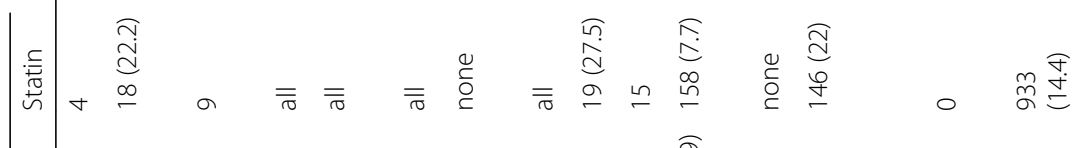

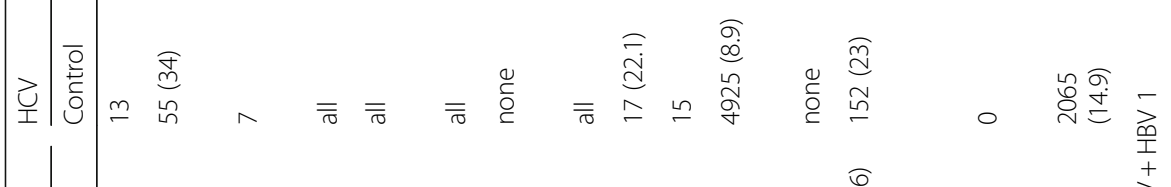

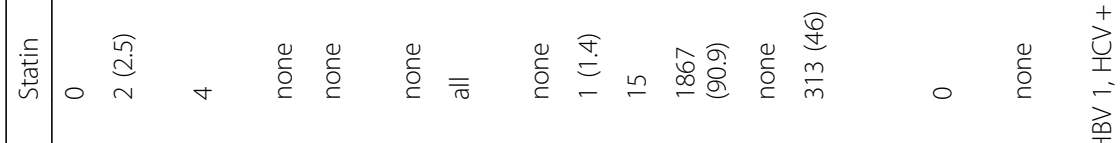

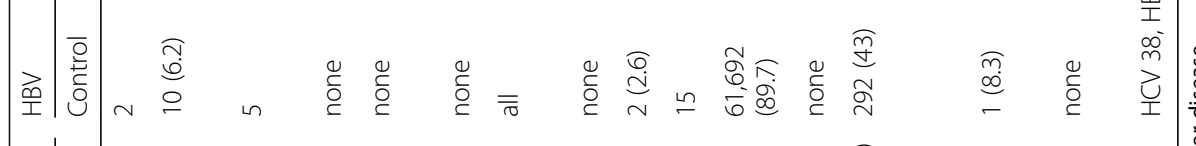

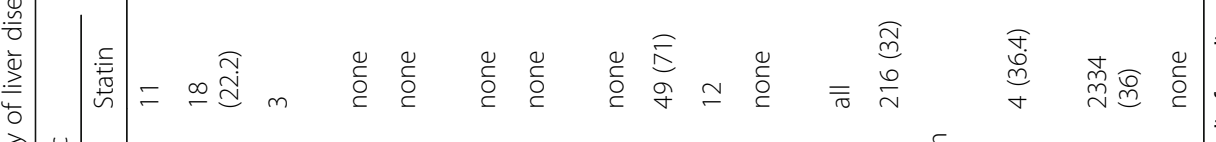

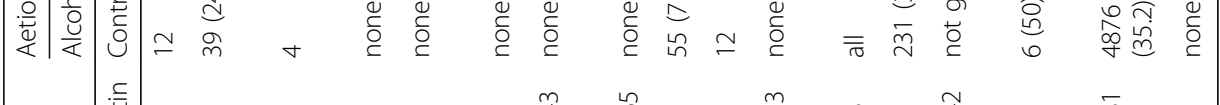

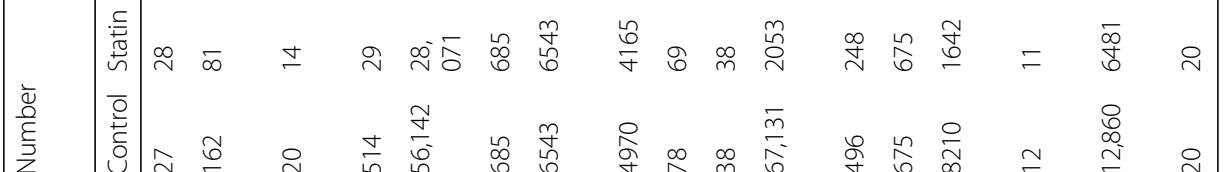

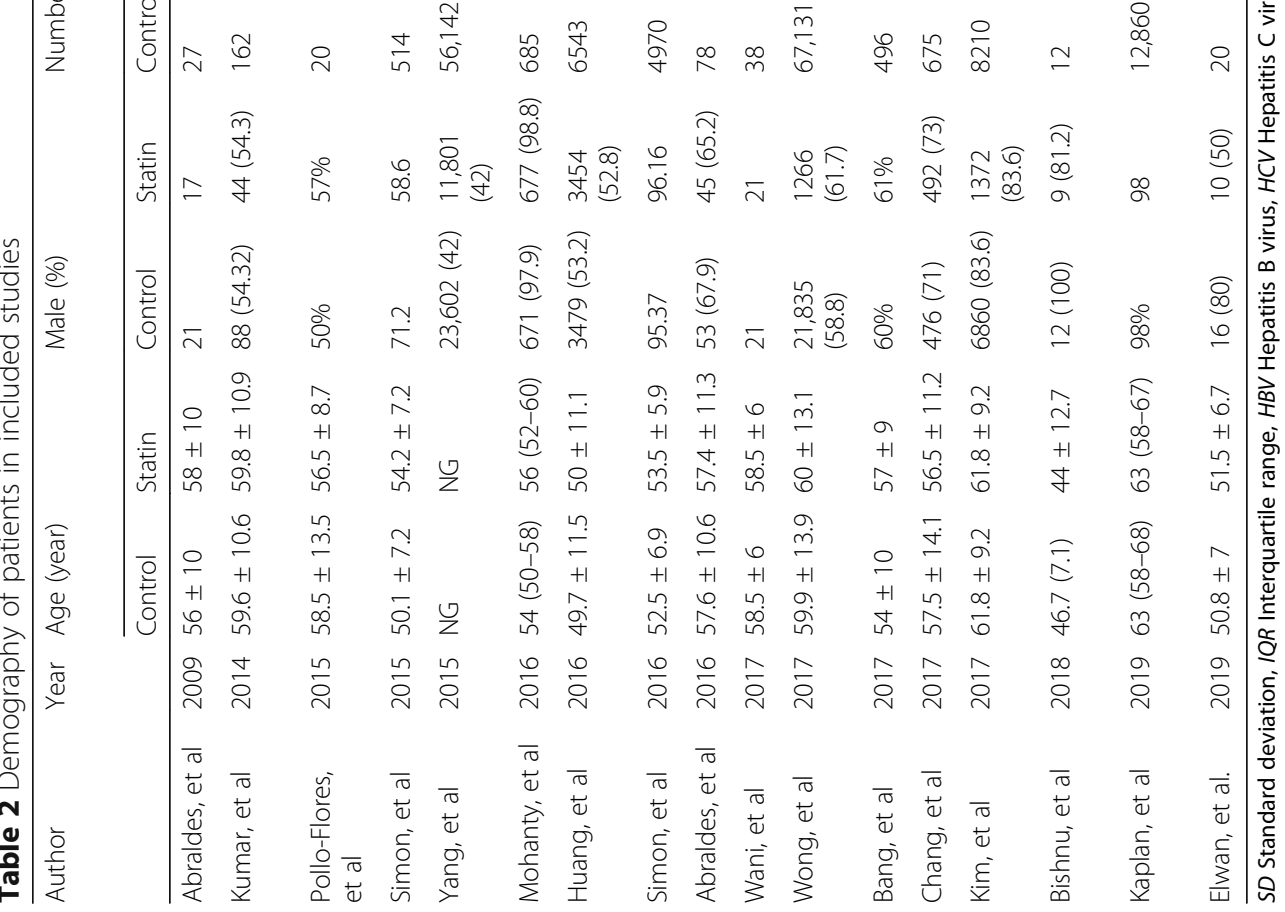


Table 3 Characteristics of included studies

\begin{tabular}{|c|c|c|c|c|c|}
\hline Author & Year & Number of patients & Study design & Statin & Follow-up duration \\
\hline Abraldes, et al & 2009 & 55 & Randomized controlled trial & simvastatin & 1 month \\
\hline Kumar, et al & 2014 & 243 & $\begin{array}{l}\text { Propensity Score Matching } \\
\text { Case-control Study }\end{array}$ & $\begin{array}{l}\text { atorvastatin, fluvastatin, lovastatin, pravastatin, } \\
\text { rosuvastatin and simvastatin }\end{array}$ & 13 years \\
\hline Simon, et al & 2015 & 543 & Cohort study & non-selected & 3.5 years \\
\hline Yang, et al & 2015 & 84,213 & $\begin{array}{l}\text { Propensity Score Matching } \\
\text { Case-control Study }\end{array}$ & Non-selected & 4 years \\
\hline Pollo-Flores, et al & 2015 & 34 & Randomized controlled trial & simvastatin & 3 months \\
\hline Huang, et al & 2016 & 13,086 & $\begin{array}{l}\text { Propensity Score Matching } \\
\text { Case-control Study }\end{array}$ & non-selected & 12 years \\
\hline Mohanty, et al & 2016 & 1370 & $\begin{array}{l}\text { Propensity Score Matching } \\
\text { Case-control Study }\end{array}$ & $\begin{array}{l}\text { atorvastatin, fluvastatin, lovastatin, pravastatin, } \\
\text { rosuvastatin and simvastatin }\end{array}$ & 14 years \\
\hline Simon, et al & 2016 & 9135 & Case-control Study & atorvastatin and fluvastatin & 14 years \\
\hline Abraldes, et al & 2016 & 147 & Randomized controlled trial & simvastatin & 2 years \\
\hline Bang, et al & 2017 & 744 & Case-control Study & non-selected & 8 years \\
\hline Chang, et al & 2017 & 1350 & $\begin{array}{l}\text { Propensity Score Matching } \\
\text { Case-control Study }\end{array}$ & non-selected & 8.5 years \\
\hline Kim, et al & 2017 & 9852 & Nested Case-control Study & $\begin{array}{l}\text { atorvastatin, lovastatin, pravastatin, rosuvastatin } \\
\text { and simvastatin }\end{array}$ & 12 years \\
\hline Wong, et al & 2017 & 69,184 & $\begin{array}{l}\text { Propensity Score Matching } \\
\text { Case-control Study }\end{array}$ & $\begin{array}{l}\text { atorvastatin, fluvastatin, lovastatin, pravastatin, } \\
\text { rosuvastatin and simvastatin }\end{array}$ & 3 years \\
\hline Wani, et al & 2017 & 76 & $\begin{array}{l}\text { Self-control Study (Prospective } \\
\text { Cohort) }\end{array}$ & simvastatin & 3 months \\
\hline Bishnu, et al & 2018 & 23 & Randomized controlled trial & atorvastatin & 1 month \\
\hline Kaplan, et al & 2019 & 19,341 & $\begin{array}{l}\text { Propensity Score Matching } \\
\text { Case-control Study }\end{array}$ & non-selected & 5.5 years \\
\hline Elwan, et al & 2019 & 40 & Randomized controlled trial & simvastatin & 1 month \\
\hline
\end{tabular}

complication, HCC could sharply increase the risk of mortality $[45,46]$. Accordingly, effect of statin on lowering the occurrence of $\mathrm{HCC}(\mathrm{HR}=0.75,95 \% \mathrm{CI}$ : $0.64-$ 0.86 ) should really alleviate the disease burden of liver cirrhosis (Fig. 3g, $I^{2}>50 \%$ ). Logically, statin could decrease the case need for liver transplantation (Fig. 3h, $\left.I^{2}<50 \%\right)$.

Incidence of adverse events didn't increase in statin users As is known to us that statin could lead to muscle injury and liver dysfunction, which might further result in myalgia and worsening of ascites. Therefore, the incidence of statin related adverse events was analysed here (Fig. 4). Based on existed studies, statin usage didn't increase the number of cases of worsened ascites (pooled OR $=0.959$, 95\% CI: $0.169-1.749, I^{2}<50 \%$ ), in comparison with control group. Myalgia events were evenly distributed between different groups (pooled $\mathrm{OR}=1.459,95 \% \mathrm{CI}$ : $5.614-8.532, I^{2}<50 \%$ ), and the frequency of myalgia was comparable no matter stain was treated or not (Fig. 4b). Besides, statin was reported to correlate with gastrointestinal problem, such as diarrhea. However, pooled data indicated that the number of diarrhea patients with statin treatment was not different from that in patients without statin treatment (pooled OR $=1.813,95 \% \mathrm{CI}$ : -7.156 - 10.782, $\left.I^{2}<50 \%\right)$. Therefore, statin might not increase risk of diarrhea in liver cirrhosis patients (Fig. 4c).

\section{Subgroup analysis by the study design of RCT versus non-RCT}

Considering the concerns about any difference of statin effects between RCT study versus. Non-RCT study, therefore, subgroup analysis by the study design (whether RCT or not) was performed when the number of included literatures was enough for this purpose. End-point events involved in this part contained mortality, decompensation events, SBP, ascites, esophageal variceal bleeding. And it indicated the results of pooled data from RCT study was not consistent with results from non-RCT study, except for decompensation events and esophageal variceal bleeding (Additional file 2: Figure S2). Compared to RCT study, non-RCT study possessed with much more objects. And well-designed non-RCT study such as Propensity Score Matching Case-control Study.

Cohort study with much more amount of patients could also offer favorable evidence for clinical practice. 


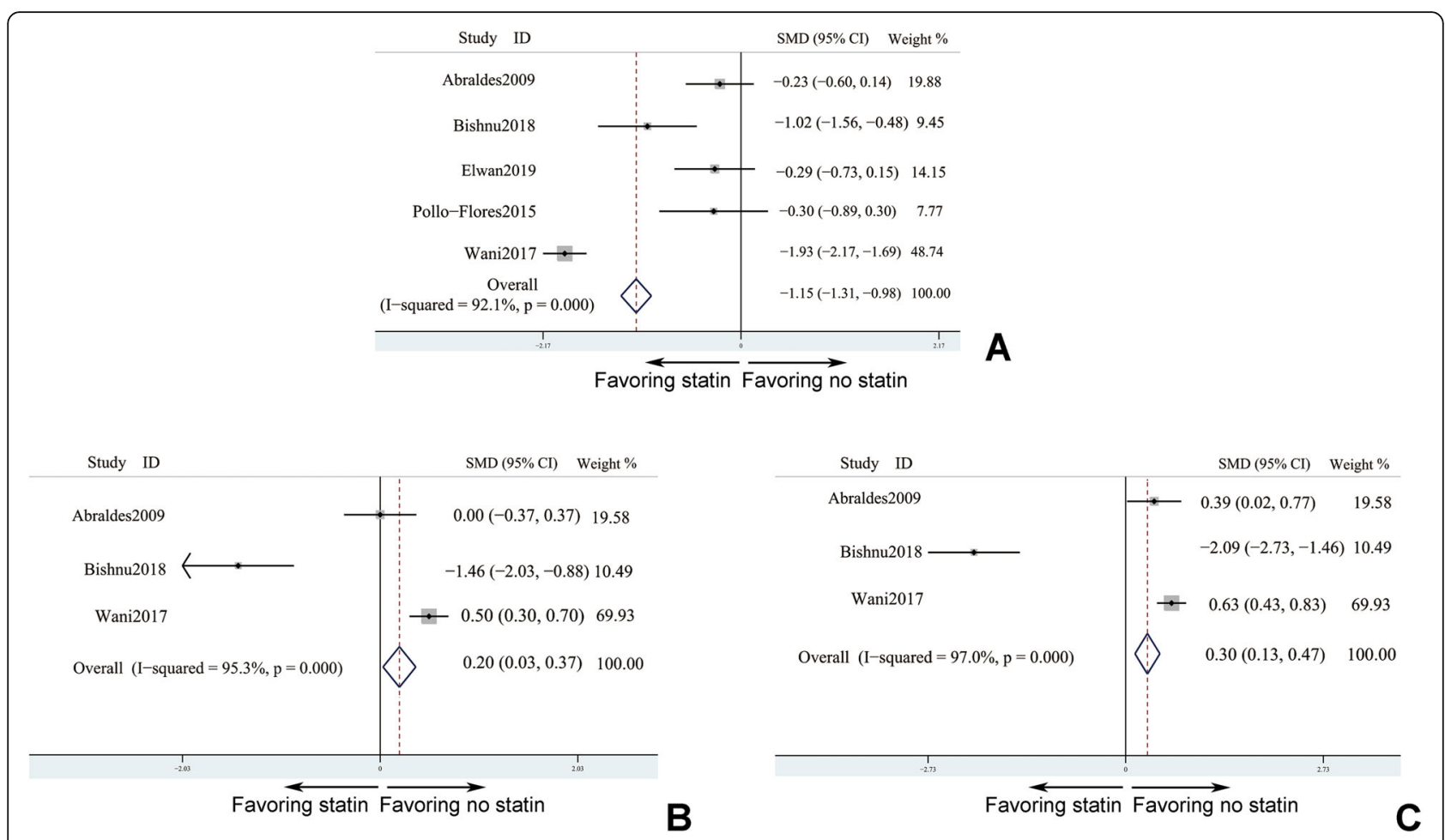

Fig. 2 Statin influenced parameters of hepatic portal vessel pressure in short-term treatment. a hepatic venous pressure gradient (HVPG); b wedged hepatic venous pressures (WHVP); c free hepatic vein pressure (FHVP). 5 studies (a) and 3 studies (b \& c) - Abraldes et al., [21]; Bishnu et al., [24]; Elwan et al., [26]; Pollo-Flores et al., [32]; and Wani et al., [35]

\section{Dose-dependent effects of statin on HCC development, decompensated cirrhosis events occurrence, and liver cirrhosis progression}

In each included studies, statin was divided into 3 doses: low dose, medium dose, and high dose. Effects of different dose of statin on liver cirrhosis were analyzed (Fig. 5). All 3 doses of statin could decrease of HCC (Fig. 5a) incidence (low dose: $\mathrm{HR}=0.459,95 \%$ CI: $0.195-0.724, I^{2}>$ 50\%; medium dose: $\mathrm{HR}=0.422$, 95\% CI: $0.235-0.609$, $I^{2}<50 \%$; high dose: HR $=0.494,95 \%$ CI: $0.329-0.66, I^{2}<$ $50 \%)$. Low dose of statin didn't influence decompensation of liver cirrhosis (HR $=0.726,95 \% \mathrm{CI}$ : $0.406-1.047$, $\left.I^{2}<50 \%\right)$. However, both medium dose and high dose of statin could decrease incidence of decompensation events of liver cirrhosis (medium dose: $\mathrm{HR}=0.554$, 95\% CI: $0.311-0.798, I^{2}<50 \%$; high dose: $\mathrm{HR}=0.31,95 \% \mathrm{CI}$ : $0.098-0.522, I^{2}>50 \%$ ). Liver puncture biopsy to evaluate liver cirrhosis pathological progression indicated that all doses of statin could mitigate liver fibrosis and sclerosis (low dose: $\mathrm{HR}=0.345,95 \% \mathrm{CI}$ : $0.32-0.37$, $I^{2}>50 \%$; medium dose: $\mathrm{HR}=0.254$, 95\% CI: $0.235-$ $0.274, I^{2}>50 \%$; high dose: $\mathrm{HR}=0.149$, 95\% CI: $0.135-$ $\left.0.164, I^{2}<50 \%\right)$. It seemed that higher dose of statin tended to have better effect on relieving pathological progression of liver cirrhosis (Fig. 5c).

\section{Publication bias analysis}

The representative publication bias analysis by Begg's test showed a symmetrical distribution of included publications $(p=0.427)$ in a funnel plot (Additional file 1 : Figure S1), and this indicated that there didn't exist publication bias among articles included in present study.

\section{Discussion}

In the present meta-analysis, 17 studies were finally included for data pooling and synthesis. Statin was proved to be effectively lowering the risk of the occurrence of decompensated liver cirrhosis such as variceal haemorrhage, encephalopathy, and spontaneous bacterial peritonitis, which was treated as life-threatening event in chronic liver cirrhosis in a long-term follow-up. Besides, statin could decrease the incidence of HCC which was a serious complication of liver cirrhosis. In addition, the dose-dependent effect of statin in liver cirrhosis was testified base on pooled data, and it indicated that statin had potential in treating chronic liver disease. Even in short-term therapeutic of statin, the hemodynamics of portal vessel was significantly improved. Since it drew concerning about the statin application in chronic liver cirrhosis might accentuate liver dysfunction, we compared the drugs related adverse events between statin 


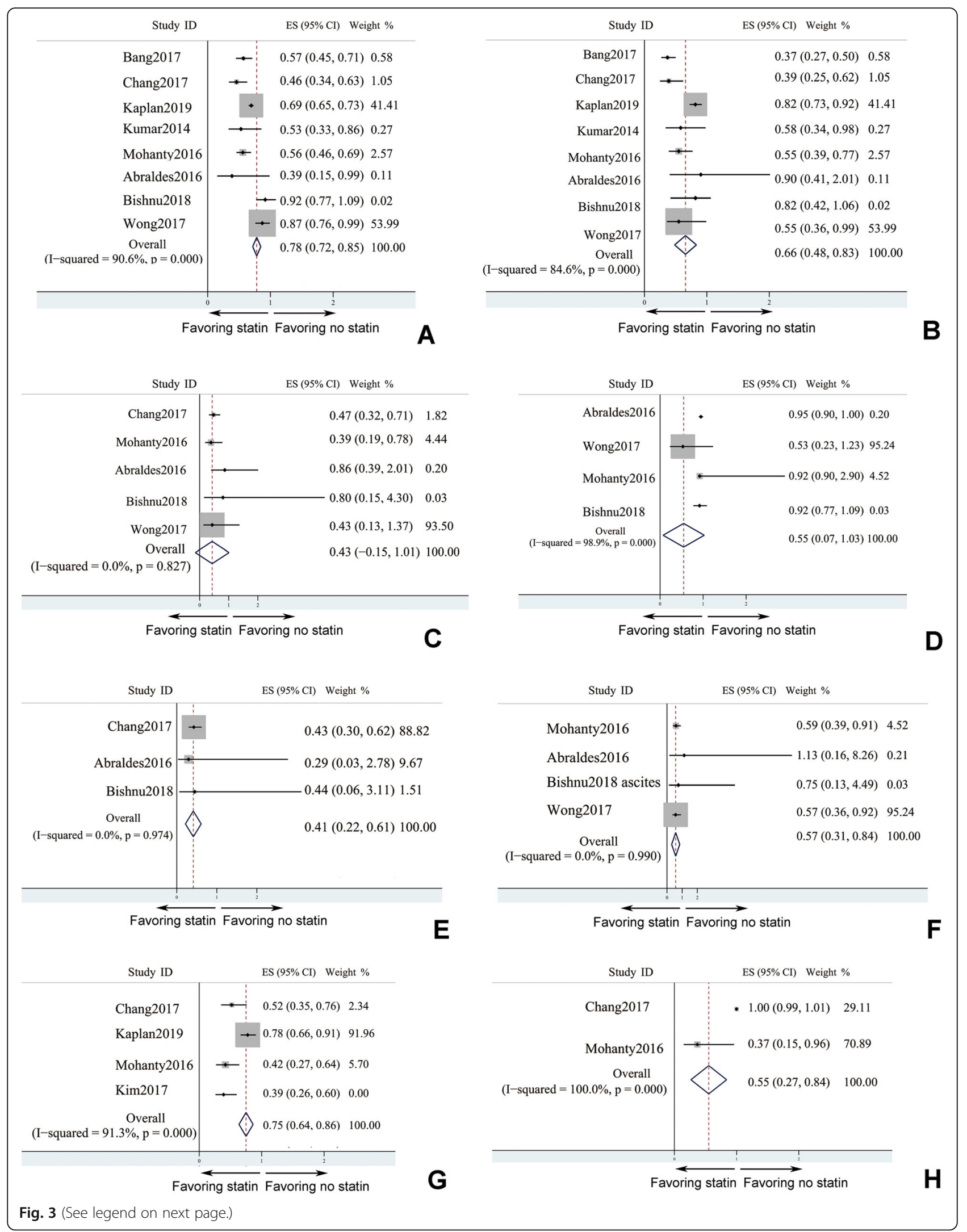


(See figure on previous page.)

Fig. 3 Prognosis of liver cirrhosis benefited from statin treatment in long termfollow-up. a mortality; b decompensation events (8 studies - Bang et al., [23]; Chang et al., [25]; Kaplan et al., [28]; Kumar et al., [30]; Mohanty et al., [31]; Abraldes et al., [22]; Bishnu et al., [24]; and Wong et al., [36]); c esophageal variceal bleeding (5 studies); $\mathbf{d}$ spontaneous bacterial peritonitis (SBP) (4 studies); e hepatic encephalopathy (HE) (3 studies); $\mathbf{f}$ ascites (4 studies); $\mathbf{g}$ HCC (hepatocellular carcinoma) development (4 studies); $\mathbf{h}$ liver transplantation rate (2 studies)

treated group and non-statin treated group. Diarrhea, myalgia, and ascites accentuation showed no difference no matter statin was used or not. This study was characterized with the largest sample size to comprehensively evaluate the efficacy and safety of statin on liver cirrhosis and its development. In spite of results mentioned above, for fear of any difference of statin effects between RCT study versus. Non-RCT study, subgroup analysis by the study design (whether RCT or not) was performed. It indicated the results of pooled data from RCT study was not consistent with results from non-RCT study, except for decompensation events and esophageal variceal bleeding. To our knowledge, similar systematic study was hardly seen before.

As one of the mostly prescribed medication, statin is widely used in the primary prevention of coronary ischemic heart disease by outstandingly inhibiting the activity of HMG-CoA. However, laboratory studies showed that statin could further attain endothelial functional improvement independently from down-of cholesterol level $[20,47]$. Previous investigation indicated that statin could improve the resilience and compliance of portal vessels by promoting the production of vascular endothelium-derived relaxing factor, namely, nitric oxide [48-52]. Furthermore, clinical studies hinted that statin could mitigate hepatic portal hypertension as well with a short therapeutic duration (mean value of follow-up period: 3 months) [21, 24, 26, 32, 35]. Moreover, statin was proved to function as a kind of free radical eliminated agent which could relieve oxidative stress reaction in liver cirrhosis progression [53, 54]. Inflammatory reaction could be suppressed by statin through inhibiting and eliminating the over-produced free radical or other pernicious by-product in liver cirrhosis $[55,56]$, and hence hepatic cell injury and fibrosis could be partly prevented from underlying this mechanism. Given myalgia (muscular damage and creatine kinase elevation) as one of the most common drug-related adverse reactions clinical studies were designed to assess its incidence in statin treated liver cirrhosis, and most of which confirmed the safety of statin use [26, 32]. Portal hypertension as a marker of decompensated liver cirrhosis could further exacerbate liver cirrhosis to form a vicious cycle [57-

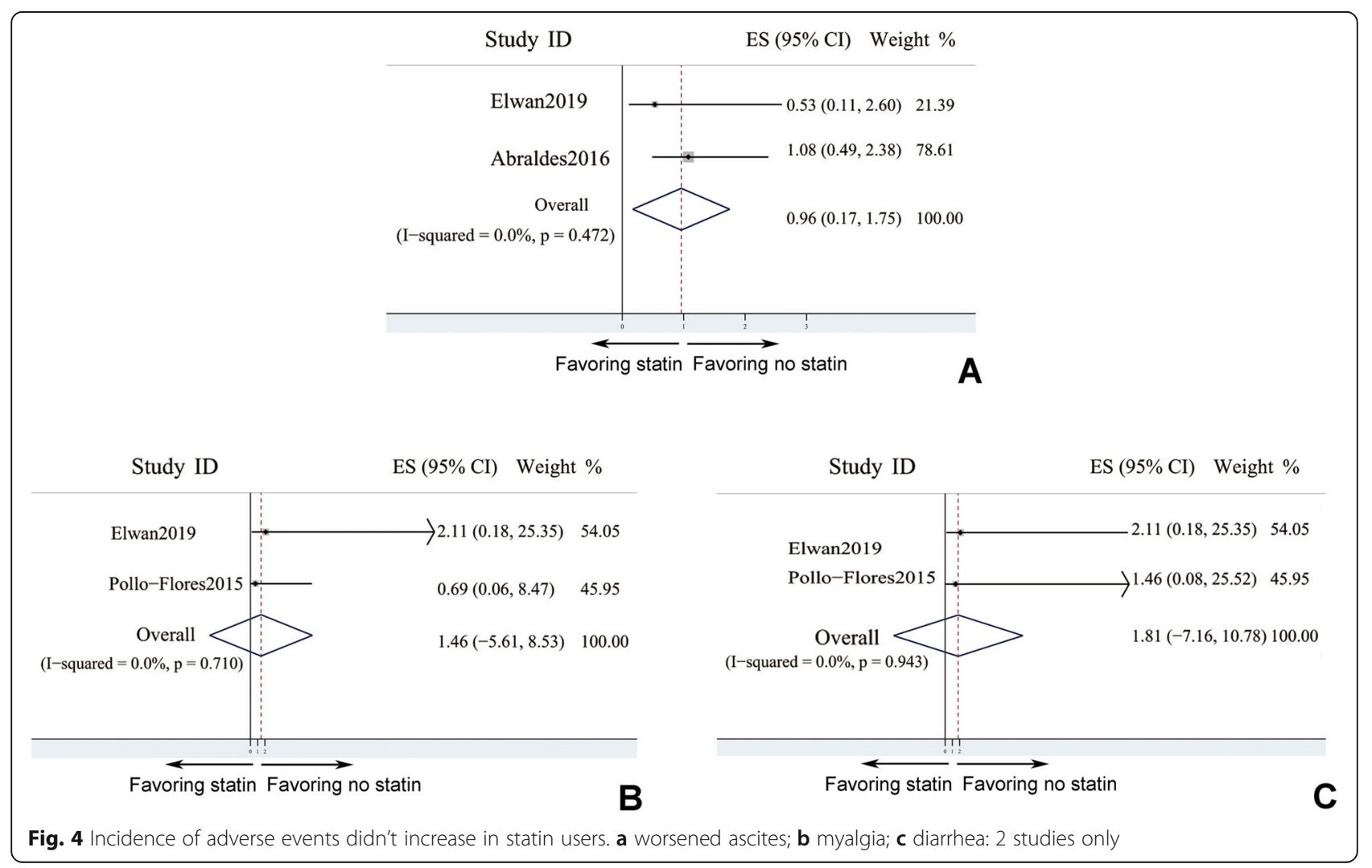




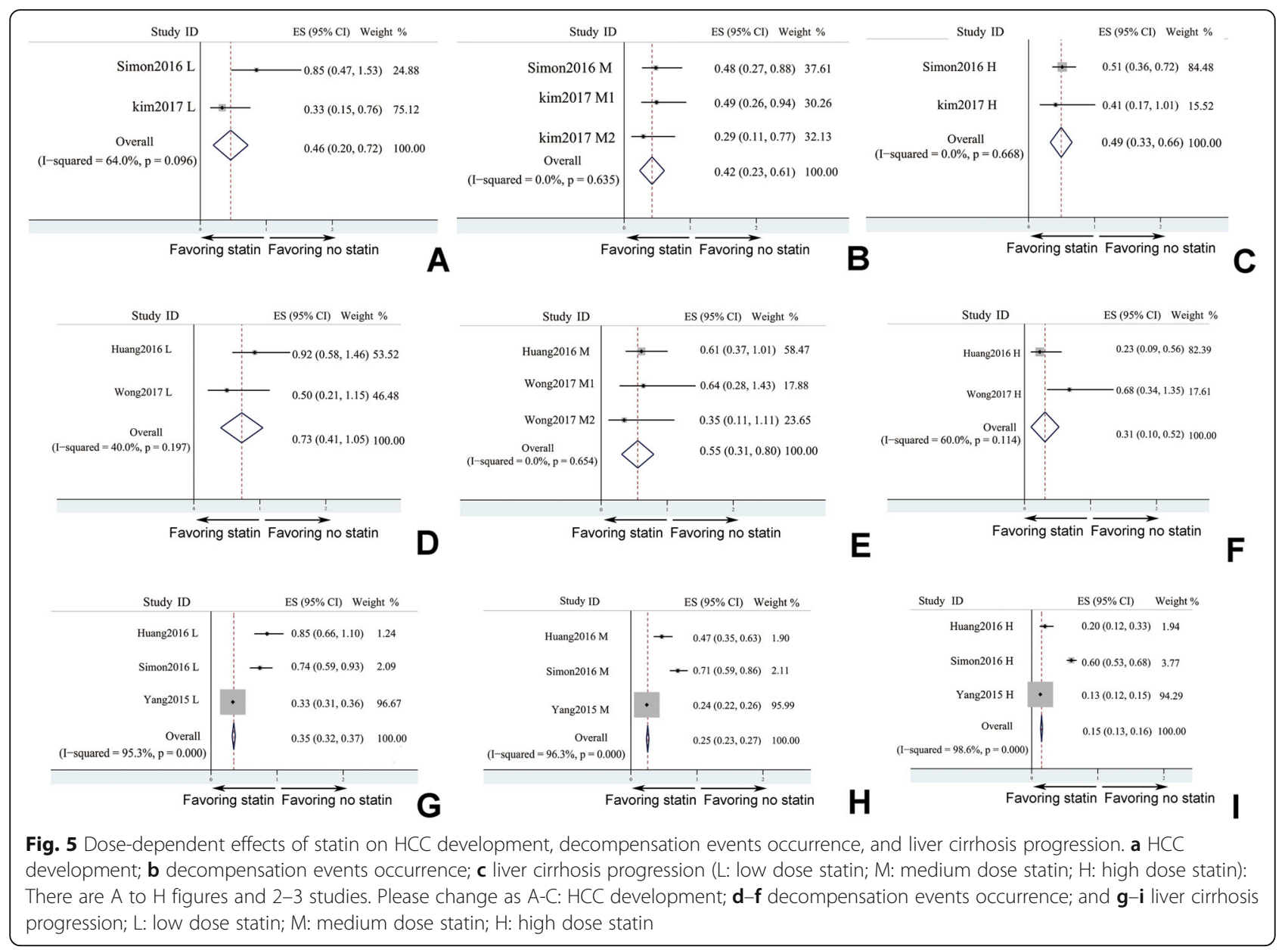

59], and statin could break this circle by lowering hepatic portal vascular pressure to improve the prognosis of liver cirrhosis. HCC could be evolved from sustained condition of liver cirrhosis [60], and statin might decrease the occurrence rate of $\mathrm{HCC}$ through slowing the development of disease course of liver cirrhosis. Studies ranging from bench to bed indicated that chronic liver cirrhosis might be a novel indication for statin treatment, and pooled data of clinical studies finally supported this viewpoint. In cardiovascular disorders, especially coronary atherosclerosis disease (CAD), statin treatment showed eminent dosedependent effects on the prognosis of CAD $[61,62]$. Similarly, statin also exhibited dose-dependent effects on HCC development, decompensated cirrhosis events occurrence, and liver cirrhosis progression. Despite low dose of statin didn't affect decompensated liver cirrhosis, both medium and high dose of statin could improve decompensated liver cirrhosis. Furthermore, higher dose of statin tended to have better effect on relieving pathological progression of liver cirrhosis.

A systematic review has already been done to quantitatively summarize effects of statin and accentuate the important role of statin in treating chronic liver disease. Based on this study, statin use is probably associated with lower risk of hepatic decompensation and mortality, and might reduce portal hypertension, in patients with chronic liver diseases [13]. Nonetheless, this study failed to evaluate the safety of statin, and the number of studies it included was less than ours. To our knowledge, similar systematic study with multi-dimension and statistical depth was hardly seen before. The quality of the present meta-analysis was guaranteed by thorough retrieval strategy, well-defined inclusion and exclusion criteria, guideline mediated literature evaluation, and strictly quantitative analysis by wellacknowledged STATA software.

\section{Limitation}

This study included 17 studies, parts of which were of characterized with observational and case-control design. The included articles had defects such as no randomization, retrospective design, and small scale, and these flaws could somehow devaluate the quality of our study. However, studies with high quality were involved with high weighting ratio, which meant that study with higher quality contributed more on the present metaanalysis. The included studies investigated liver disease 
with different aetiology, such as alcoholic liver disease, NAFLD, HBV, HCV, and so on. As a result, the heterogeneity of liver cirrhosis aetiology at baseline might lead to bias of treatment response to statin. In addition, the present regarded different kinds of statin, such as simvastatin, artovastatin, fluvastatin, and so on, as a whole, however, the head-to-head comparison of effects of different kinds of statin on liver cirrhosis should be discussed in future. Perhaps, a network meta-analysis could solve this problem. Furthermore, the limited number of articles eligible for different research target made sensitivity analysis not applicable. Additionally, patients with $\beta$-blocker administration or comorbidities of chronic kidney disease were also susceptible to exacerbated hepatic function, and these confounding factors were not presented in the included studies. Therefore, riskstratified analysis couldn't be carried out. Consequently, large scale, prospective, multi-center, and randomized clinical trials are still highly needed with clearly reported confounding factors.

\section{Conclusion}

In the present study, statin was proved to be effectively lowering the risk of the occurrence of decompensated liver cirrhosis such as encephalopathy and ascites, which was treated as life-threatening event in chronic liver cirrhosis in a long-term follow-up. Unfortunately, statin might have no effect on variceal haemorrhage and spontaneous bacterial peritonitis. Besides, statin could decrease the incidence of HCC which was a serious complication of liver cirrhosis. In addition, the dose-dependent effect of statin in liver cirrhosis was testified base on pooled data, and it indicated that higher dose of statin tended to have better effect on relieving pathological progression of liver cirrhosis. Even in short-term therapeutic of statin, the hemodynamics of portal vessel was significantly improved. Drugs related adverse events between statin treated group and non-statin treated group show no difference. This study was characterized with the largest sample size to comprehensively evaluate the efficacy and safety of statin on liver cirrhosis and its development.

\section{Supplementary information}

Supplementary information accompanies this paper at https://doi.org/10. 1186/s12876-019-1147-1.

\section{Additional file 1: Figure S1. Typical diagram of publication bias} analysis.

Additional file 2: Figure S2. Subgroup analysis by the study design of $R C T$ versus non-RCT. A: mortality in RCT study; $B$ : mortality in non-RCT study; C: decompensation events in RCT study; D: decompensation events in non-RCT study; E: spontaneous bacterial peritonitis (SBP) in RCT study; F: spontaneous bacterial peritonitis (SBP) in non-RCT study; G: ascites in RCT study; H: ascites in non-RCT study; l: esophageal variceal bleeding in RCT study; J: esophageal variceal bleeding in non-RCT study.

\section{Abbreviations}

CAD: Coronary Atherosclerosis Disease; Cl: Confidence interval; FHVP: Free Hepatic Vein Pressure; HCC: Hepatocellular carcinoma; HMG-CoA: 3-hydroxy3-methylglutaryl co-enzyme A; HR: Hazard Ratio; HVPG: Hepatic Venous Pressure Gradient; OR: Odds Ratio; PRISMA: Preferred Reporting Items for Systematic Reviews and Meta-Analyses; SBP: Spontaneous bacterial peritonitis; SMD: Standard Mean Difference; WHVP: Wedged Hepatic Venous Pressures

\section{Acknowledgements \\ None.}

\section{Authors' contributions}

$Y G$ and $X Y$ contributed to the study design. $Y G, X Y, H L$ and $D L$ collected the data and performed the data analysis. All authors prepared the manuscript. All authors have read and approved the manuscript in its current state.

\section{Funding}

None.

\section{Availability of data and materials}

The datasets used and/or analysed during the current study are available from the corresponding author on reasonable request.

Ethics approval and consent to participate

This is a meta-analysis. So the ethics approval is not applicable.

Consent for publication

Not applicable.

Competing interests

The authors declare that they have no competing interests.

\section{Author details}

${ }^{1}$ Department of Hepatobiliary and Pancreatic Surgery, First Hospital of Jilin University, Changchun, Jilin, China. ${ }^{2}$ Department of Traditional Chinese Medicine, First Hospital of Jilin University, Changchun, Jilin, China. ${ }^{3}$ Department of Pediatric Respiratory II, First Hospital of Jilin University, No. 1 Xinmin Street, Changchun 130021, Jilin, China.

Received: 19 September 2019 Accepted: 17 December 2019

Published online: 30 December 2019

\section{References}

1. Tsochatzis EA, Bosch J, Burroughs AK. Liver cirrhosis. Lancet (London, England). 2014;383(9930):1749-61.

2. D'Amico G, Garcia-Tsao G, Pagliaro L. Natural history and prognostic indicators of survival in cirrhosis: a systematic review of 118 studies. Hepatol. 2006;44(1):217-31.

3. D'Amico G, Morabito A, D'Amico M, Pasta L, Malizia G, Rebora P, et al. Clinical states of cirrhosis and competing risks. J Hepatol. 2018;68(3):563-76.

4. Younossi Z, Henry L. Contribution of alcoholic and nonalcoholic fatty liver disease to the burden of liver-related morbidity and mortality. Gastroenterology. 2016;150(8):1778-85.

5. Schuppan D, Afdhal NH, et al. Lancet (London, England). 2008;371(9615): 838-51.

6. Chou R, Dana T, Blazina I, Daeges M, Jeanne TL. Statins for prevention of cardiovascular disease in adults: evidence report and systematic review for the US preventive services task force. JAMA. 2016;316(19):2008-24.

7. Oesterle A, Laufs U, Liao JK. Pleiotropic effects of statins on the cardiovascular system. Circ Res. 2017;120(1):229-43.

8. Arab JP, Shah VH. Statins and portal hypertension: A tale of two models. Hepatology (Baltimore, Md). 2016;63(6):2044-7.

9. Meireles CZ, Pasarin M, Lozano JJ, Garcia-Caldero H, Gracia-Sancho J, GarciaPagan JC, et al. Simvastatin Attenuates Liver Injury in Rodents with Biliary Cirrhosis Submitted to Hemorrhage/Resuscitation. Shock (Augusta, Ga). 2017:47(3):370-7. 
10. Tripathi DM, Vilaseca M, Lafoz E, Garcia-Caldero H, Viegas Haute G, Fernandez-Iglesias A, et al. Simvastatin prevents progression of acute on chronic liver failure in rats with cirrhosis and portal hypertension. Gastroenterology. 2018;155(5):1564-77.

11. Vargas Jl, Arrese M, Shah VH, Arab JP. Use of statins in patients with chronic liver disease and cirrhosis: current views and prospects. Curr Gastroenterol Rep. 2017;19(9):43

12. Kamal S, Khan MA, Seth A, Cholankeril G, Gupta D, Singh U, et al. Beneficial effects of statins on the rates of hepatic fibrosis, hepatic Decompensation, and mortality in chronic liver disease: a systematic review and meta-analysis. Am J Gastroenterol. 2017;112(10):1495-505.

13. Kim RG, Loomba R, Prokop LJ, Singh S. Statin Use and Risk of Cirrhosis and Related Complications in Patients With Chronic Liver Diseases: A Systematic Review and Meta-analysis. Clin Gastroenterol Hepatol. 2017;15(10):1521-30.e8.

14. Pose E, Trebicka J, Mookerjee RP, Angeli P, Gines P. Statins: old drugs as new therapy for liver diseases? J Hepatol. 2019;70(1):194-202.

15. Kasia C, Scaglione SJ. Patients with chronic liver disease/cirrhosis should not take statin medications. Clin Liver Dis. 2019;13(4):106-10.

16. Unger LW, Forstner B, Schneglberger S, Muckenhuber M, Eigenbauer E, Bauer $\mathrm{D}$, et al. Guideline-conform statin use reduces overall mortality in patients with compensated liver disease. Sci Rep. 2019;9(1):11674.

17. Patel SS, Guzman LA, Lin FP, Pence T, Reichman T, John B, et al. Utilization of aspirin and statin in management of coronary artery disease in patients with cirrhosis undergoing liver transplant evaluation. Liver Transpl. 2018; 24(7):872-80.

18. Sigler MA, Congdon L, Edwards KL. An evidence-based review of statin use in patients with nonalcoholic fatty liver disease. Clin Med Insights Gastroenterol. 2018;11:1179552218787502.

19. Wright AP, Adusumalli $S$, Corey KE. Statin therapy in patients with cirrhosis. Frontline Gastroenterol. 2015;6(4):255-61.

20. Sirtori CR. The pharmacology of statins. Pharmacol Res. 2014;88:3-11.

21. Abraldes JG, Albillos A, Banares R, Turnes J, Gonzalez R, Garcia-Pagan JC, et al. Simvastatin lowers portal pressure in patients with cirrhosis and portal hypertension: a randomized controlled trial. Gastroenterol. 2009;136(5):1651-8.

22. Abraldes JG, Villanueva C, Aracil C, Turnes J, Hernandez-Guerra M, Genesca J, et al. Addition of Simvastatin to Standard Therapy for the Prevention of Variceal Rebleeding Does Not Reduce Rebleeding but Increases Survival in Patients With Cirrhosis. Gastroenterol. 2016;150(5):1160-70.e3.

23. Bang UC, Benfield T, Bendtsen F. Reduced risk of decompensation and death associated with use of statins in patients with alcoholic cirrhosis. A nationwide case-cohort study. Aliment Pharmacol Ther. 2017;46(7):673-80.

24. Bishnu S, Ahammed SM, Sarkar A, Hembram J, Chatterjee S, Das K, et al. Effects of atorvastatin on portal hemodynamics and clinical outcomes in patients with cirrhosis with portal hypertension: a proof-of-concept study. Eur J Gastroenterol Hepatol. 2018;30(1):54-9.

25. Chang FM, Wang YP, Lang HC, Tsai CF, Hou MC, Lee FY, et al. Statins decrease the risk of decompensation in hepatitis $B$ virus- and hepatitis $C$ virus-related cirrhosis: A population-based study. Hepatology (Baltimore, Md). 2017:66(3):896-907.

26. Elwan N, Salah R, Hamisa M, Shady E, Hawash N, Abd-Elsalam S. Evaluation of portal pressure by doppler ultrasound in patients with cirrhosis before and after simvastatin administration - a randomized controlled trial. F1000Research. 2018;7:256.

27. Huang YW, Lee CL, Yang SS, Fu SC, Chen YY, Wang TC, et al. Statins reduce the risk of cirrhosis and its Decompensation in chronic hepatitis B patients: a Nationwide cohort study. Am J Gastroenterol. 2017;111(7):976.

28. Kaplan DE, Serper MA, Mehta R, Fox R, John B, Aytaman A, et al. Effects of Hypercholesterolemia and Statin Exposure on Survival in a Large National Cohort of Patients With Cirrhosis. Gastroenterology. 2019;156(6):1693-706.e12.

29. Kim G, Jang SY, Nam CM, Kang ES. Statin use and the risk of hepatocellular carcinoma in patients at high risk: a nationwide nested case-control study. J Hepatol. 2018;68(3):476-84.

30. Kumar S, Grace ND, Qamar AA. Statin use in patients with cirrhosis: a retrospective cohort study. Dig Dis Sci. 2014;59(8):1958-65.

31. Mohanty A, Tate JP, Garcia-Tsao G. Statins Are Associated With a Decreased Risk of Decompensation and Death in Veterans With Hepatitis C-Related Compensated Cirrhosis. Gastroenterology. 2016;150(2):430-40.e1.

32. Pollo-Flores $P$, Soldan $M$, Santos UC, Kunz DG, Mattos DE, da Silva AC, et al. Three months of simvastatin therapy vs. placebo for severe portal hypertension in cirrhosis: a randomized controlled trial. Dig Liver Dis. 2015; 47(11):957-63.
33. Simon TG, Bonilla H, Yan P, Chung RT, Butt AA. Atorvastatin and fluvastatin are associated with dose-dependent reductions in cirrhosis and hepatocellular carcinoma, among patients with hepatitis C virus: Results from ERCHIVES. Hepatology (Baltimore, Md). 2016;64(1):47-57.

34. Simon TG, King LY, Zheng H, Chung RT. Statin use is associated with a reduced risk of fibrosis progression in chronic hepatitis C. J Hepatol. 2015; 62(1):18-23.

35. Wani ZA, Mohapatra S, Khan AA, Mohapatra A, Yatoo GN. Addition of simvastatin to carvedilol non responders: a new pharmacological therapy for treatment of portal hypertension. World J Hepatol. 2017;9(5):270-7.

36. Wong JC, Chan HL, Tse YK, Yip TC, Wong WW, Wong GL. Statins reduce the risk of liver decompensation and death in chronic viral hepatitis: a propensity score weighted landmark analysis. Aliment Pharmacol Ther. 2017:46(10):1001-10.

37. Yang YH, Chen WC, Tsan YT, Chen MJ, Shih WT, Tsai YH, et al. Statin use and the risk of cirrhosis development in patients with hepatitis $C$ virus infection. J Hepatol. 2015;63(5):1111-7.

38. Shamseer L, Moher D, Clarke M, Ghersi D, Liberati A, Petticrew M, et al. Preferred reporting items for systematic review and meta-analysis protocols (PRISMA-P) 2015: elaboration and explanation. BMJ (Clinical research ed). 2015;350:g7647.

39. Cholesterol Treatment Trialists' Collaboration. Efficacy and safety of statin therapy in older people: a meta-analysis of individual participant data from 28 randomised controlled trials. Lancet (London, England). 2019;393(10170):407-15.

40. Wan S, Huang C, Zhu X. Systematic review with a meta-analysis: clinical effects of statins on the reduction of portal hypertension and variceal haemorrhage in cirrhotic patients. BMJ Open. 2019;9(7):e030038.

41. Choi HD, Chae SM. Comparison of efficacy and safety of combination therapy with statins and omega-3 fatty acids versus statin monotherapy in patients with dyslipidemia: a systematic review and meta-analysis. Medicine. 2018;97(50):e13593.

42. He Y, Li X, Gasevic D, Brunt E, McLachlan F, Millenson M, et al. Statins and multiple noncardiovascular outcomes: umbrella review of meta-analyses of observational studies and randomized controlled trials. Ann Intern Med. 2018;169(8):543-53.

43. Ma X, Sun D, Li C, Ying J, Yan Y. Statin use and virus-related cirrhosis: a systemic review and meta-analysis. Clin Res Hepatol Gastroenterol. 2017; 41(5):533-42.

44. Naci H, Brugts J, Ades T. Comparative tolerability and harms of individual statins: a study-level network meta-analysis of 246955 participants from 135 randomized, controlled trials. Circ Cardiovasc Qual Outcomes. 2013;6(4):390-9.

45. Ascione A, Fontanella L, Imparato M, Rinaldi L, De Luca M. Mortality from cirrhosis and hepatocellular carcinoma in Western Europe over the last 40 years. Liver Int. 2017;37(8):1193-201.

46. Llovet JM, Burroughs A, Bruix J. Hepatocellular carcinoma. Lancet (London, England). 2003;362(9399):1907-17.

47. Thompson PD, Panza G, Zaleski A, Taylor B. Statin-associated side effects. J Am Coll Cardiol. 2016;67(20):2395-410.

48. Baspinar O, Bayram F, Korkmaz S, Aksu M, Kocer D, Dizdar OS, et al. The effects of statin treatment on adrenal and sexual function and nitric oxide levels in hypercholesterolemic male patients treated with a statin. J Clin Lipidol. 2016;10(6):1452-61.

49. Forstermann U, Sessa WC. Nitric oxide synthases: regulation and function. Eur Heart J. 2012;33(7):829-37 37a-37d.

50. Vincenzo LM, Marcos P, Meireles CZ, Rosa M, Aina RV, Diana H, et al. Effects of simvastatin administration on rodents with lipopolysaccharide-induced liver microvascular dysfunction. Hepatology (Baltimore, Md). 2013;57(3): 1172-81.

51. Trocha M, Merwid-Lad A, Szuba A, Chlebda E, Piesniewska M, Sozanski T, et al. Effect of simvastatin on nitric oxide synthases (eNOS, iNOS) and arginine and its derivatives (ADMA, SDMA) in ischemia/reperfusion injury in rat liver. Pharmacol Rep. 2010;62(2):343-51.

52. Zafra C, Abraldes JG, Turnes J, Berzigotti A, Fernandez M, Garca-Pagan JC, et al. Simvastatin enhances hepatic nitric oxide production and decreases the hepatic vascular tone in patients with cirrhosis. Gastroenterology. 2004; 126(3):749-55.

53. Costa S, Reina-Couto M, Albino-Teixeira A, Sousa T. Statins and oxidative stress in chronic heart failure. Rev Port Cardiol. 2016;35(1):41-57.

54. Lee SH, Choi NY, Yu HJ, Park J, Choi H, Lee KY, et al. Atorvastatin protects NSC-34 motor neurons against oxidative stress by activating PI3K, ERK and free radical scavenging. Mol Neurobiol. 2016;53(1):695-705. 
55. Athyros VG, Alexandrides TK, Bilianou H, Cholongitas E, Doumas M, Ganotakis ES, et al. The use of statins alone, or in combination with pioglitazone and other drugs, for the treatment of non-alcoholic fatty liver disease/non-alcoholic steatohepatitis and related cardiovascular risk. An expert panel statement. Metab Clin Exp. 2017;71:17-32.

56. Schierwagen R, Uschner FE, Magdaleno F, Klein S, Trebicka J. Rationale for the use of statins in liver disease. Am J Physiol Gastrointest Liver Physiol. 2017;312(5):G407-g12.

57. Chen Z, Yu R, Xiong Y, Du F, Zhu S. A vicious circle between insulin resistance and inflammation in nonalcoholic fatty liver disease. Lipids Health Dis. 2017;16(1):203

58. Franceschini L, Realdon S, Marcolongo M, Mirandola S, Bortoletto G, Alberti A. Reciprocal interference between insulin and interferon-alpha signaling in hepatic cells: a vicious circle of clinical significance? Hepatology (Baltimore, Md). 2011;54(2):484-94.

59. Zhao TY, Su LP, Ma CY, Zhai XH, Duan ZJ, Zhu Y, et al. IGF-1 decreases portal vein endotoxin via regulating intestinal tight junctions and plays a role in attenuating portal hypertension of cirrhotic rats. BMC Gastroenterol. 2015;15:77.

60. Fattovich G, Stroffolini T, Zagni I, Donato F. Hepatocellular carcinoma in cirrhosis: incidence and risk factors. Gastroenterology. 2004;127(5):S35-50.

61. Barbarash O, Gruzdeva O, Uchasova E, Belik E, Dyleva Y, Karetnikova V. Dosedependent effects of atorvastatin on myocardial infarction. Drug Des Devel Ther. 2015;9:3361-8

62. Henein $M$, Granasen $G$, Wiklund U, Schmermund A, Guerci A, Erbel R, et al. High dose and long-term statin therapy accelerate coronary artery calcification. Int J Cardiol. 2015;184:581-6.

\section{Publisher's Note}

Springer Nature remains neutral with regard to jurisdictional claims in published maps and institutional affiliations.

Ready to submit your research? Choose BMC and benefit from:

- fast, convenient online submission

- thorough peer review by experienced researchers in your field

- rapid publication on acceptance

- support for research data, including large and complex data types

- gold Open Access which fosters wider collaboration and increased citations

- maximum visibility for your research: over $100 \mathrm{M}$ website views per year

At $\mathrm{BMC}$, research is always in progress.

Learn more biomedcentral.com/submissions 